\title{
FAKTOR-FAKTOR YANG BERHUBUNGAN DENGAN KEJADIAN ASFIKSIA PADA BAYI BARU LAHIR DI RS MUHAMMADIYAH PALEMBANG TAHUN 2017
}

\author{
Sri Handayani ${ }^{1}{ }^{\text {Fitriana }}{ }^{2}$ \\ Program Studi D III Kebidanan STIKES ‘Aisyiyah Palembang \\ Jl. Kol H. Burlian M. Husin Kel. Karya Baru Kec. Alang-alang Lebar Km 7,5 Palembang \\ Email : fit.trianaa@gmail.com
}

\begin{abstract}
Abstrak
Asfiksia neonatorum merupakan kegagalan napas secara spontan dan teratur pada saat lahir atau beberapa saat setelah saat lahir yang ditandai dengan hipoksemia, dan asidosis, dengan gejala bayi tidak segera menangis sesudah lahir. Tujuan penelitian ini adalah untuk mengetahui faktor-faktor yang berhubungan dengan kejadian asfiksia neonatorum pada bayi baru lahir di Rumah Sakit Muhammadiyah Palembang Tahun 2017. Penelitian ini menggunakan metode kuantitatif yang bersifat deskriptif analitik dengan pendekatan retrospektif. Pengambilan sampel menggunakan teknik simple random sampling sebanyak 81 bayi. Berdasarkan uji chi-square didapatkan hasil bahwa tidak ada hubungan yang bermakna antara kejadian asfiksia dan ada hubungan yang bermakna antara umur kehamilan ibu ( $p$ value $=0,424)$ dan berat bayi baru lahir $(p$ value $=0,000)$ dengan kejadian asfiksia.
\end{abstract}

Kata kunci $\quad$ : Faktor-faktor yang berhubungan, Kejadian Asfiksia.

\begin{abstract}
Asphyxia neonatorum is the failure of breath spontaneous and regular when in birth or shortly after birth characterized by hypoxemia and acidosis, with symptoms the baby does not cry immediately after birth. The aim of this study was to determine the factors associated with the incidence of neonatal asphyxia on newborns baby at Muhammadiyah Hospital Palembang in 2017. This study used a quantitative method that was descriptive analytic with retrospective approach. The sampling taken using simple random sampling technique as many as 81 babies. Based on the chi-square test was obtained the result that there was no significant relationship between the incidence of asphyxia and there was a significant relationship between pregnancy age $(p$ value $=0.424)$ and the weight of newborns baby ( $p$ value $=0.000)$ with the incidence of asphyxia.
\end{abstract}

Keywords : Associated factors, Asphyxia incidence. 


\section{PENDAHULUAN}

Masa neonatal adalah masa sejak lahir sampai dengan 4 minggu (28 hari) sesudah kelahiran. Neonatus adalah bayi berumur 0 (baru lahir) sampai dengan usia 28 hari. Neonatus dini adalah bayi berusia 07 hari. Neonatus lanjut adalah bayi berusia 0-28 hari (Wafi Nur Muslihatun, 2010).

Asfikisia merupakan salah satu penyebab mortalitas dan morbiditas bayi baru lahir dan akan membawa berbagai dampak pada periode neonatal baik di negara berkembang maupun di negara maju. Negara maju angka kejadian asfiksia berkisar antara $1-1,5 \%$ dan berhubungan dengaan masa gestasi dan berat lahir. Negara berkembang angka kejadian bayi asfiksia lebih tinggi dibandingkan di negara maju karena pelayanan antenatal yang masih kurang memadai. Sebagian besar bayi asfiksia tersebut tidak memperoleh penanganan yang adekuat sehingga banyak diantaranya meninggal.

Pelayanan kesehatan maternal dan neonatal merupakan salah satu unsur penentu status kesehatan. Pelayanan kesehatan neonatal dimulai sebelum bayi dilahirkan, melalui pelayanan kesehatan yang diberikan kepada ibu hamil. Pertumbuhan dan perkembangan bayi periode neonatal merupakan periode yang paling kritis karena dapat menyebabkan kesakitan dan kematian bayi. Kematian perinatal terbanyak disebabkan oleh asfiksia. Hal ini ditemukan di rumah sakit rujukan di Indonesia (Setianingrum, 2014).

Berdasarkan data dari World Health Organization (WHO) 2013, jumlah kelahiran bayi hidup di Indonesia pada tahun 2010 adalah 4.371.800, dengan kelahiran prematur sebanyak 675.700 (15,5 per 100 kelahiran hidup) dan angka kematian sebesar 32.400 (nomor 8 peneyebab kematian di Indonesia).

Berdasarkan Survei Demografi dan Kesehatan Indonesia (SDKI) Angka Kematian Bayi di Indonesia Tahun 2012 diestimasi sebesar 32 per 1.000 kelahiran hidup, untuk Propinsi Sumatera Selatan sebesar 29 per 1.000 kelahiran hidup (SDKI,
2012). Untuk Kota Palembang, berdasarkan laporan program anak, jumlah kematian bayi di Tahun 2013 sebanyak 168 kematian bayi dari 29.911 kelahiran hidup (Profil Seksi Pelayanan Kesehatan Dasar, 2013).

Angka Kematian Bayi (AKB) di Indonesia tahun 2012 diestimasi sebesar 32 per 1.000 kelahiran hidup, sedangkan untuk Propinsi Sumatera Selatan sebesar 29 per 1.000 kelahiran hidup (SDKI, 2012). Berdasarkan laporan program anak untuk kota Palembang jumlah kematian bayi di tahun 2015 sebanyak 8 kematian bayi dari 29.011 atau 0.28 per 1000 kelahiran hidup (Profil Seksi Pelayanan Kesehatan Dasar, 2015). Penyebab kematian antara lain adalah BBLR, down syndrome, infeksi neonatus, perdarahan intrakranial, sianosis, kelainan jantung, respiratory distress syndrome, post op hidrosefalus dan lainnya.

Angka Kematian Balita (AKABA) Menurut batasan Bidan Praktek Swasta yang dimaksud angka ini adalah jumlah anak yang dilahirkan pada tahun tertentu dan meninggal sebelum mencapai usia 5 tahun, dinyatakan sebagai angka per 1.000 kelahiran hidup anak dan mereflesikan kondisi sosial, ekonomi dan lingkungan anak-anak bertempat tinggal termasuk kesehatanya. Berdasarkan SDKI 2012, AKABA Indonesia sekitar 40 per 1.000 kelahiran hidup, sedangkan Provinsi Sumatera Selatan sebesar 37 per 1.000 kelahiran hidup (SDKI, 2012). Jumlah Kematian Balita di Kota Palembang tahun 2015 sebanyak 2 orang balita per 29.011 kelahiran hidup atau 0.07 per 1.000 kelahiran hidup (Profil Seksi Pelayanan Kesehatan Dasar, 2015). Penyebab kematian digolongkan antara lain hisprung, bronk pneumonia, suspek meningits, kecelakaan, dan lainnya.

Umur kehamilan ibu juga merupakan faktor yang berhubungan dengan kejadian asfiksia neonatorum. Hal ini sejalan dengan penelitian yang dilakukan oleh Dwi Mardiyaningrum di Banjarnegara menunjukkan bahwa umur kehamilan ada hubungan dengan kejadian asfiksia neonatorum di mana umur kehamilan $\rho$ 
$(0,001) \quad \rho$ dengan nilai $<0,005.16$ Distribusi responden umur kehamilan sebagian besar 37-42 minggu. Hal ini sejalan dengan pendapat Arif Z. R, Kristiyanasari, yang menyatakan bayi yang cukup bulan dan terlihat normal di bagian luar belum tentu sempurna bagian JIDAN Jurnal Ilmiah Bidan ISSN : 2339-1731 Volume 2 Nomor 1. Januari - Juni 201471 dalamnya, termasuk gangguan pernafasan.

$$
\text { Menurut hasil penelititian }
$$

Nopitamalasari tahun 2013 yang berjudul hubungan antara faktor ibu dengan kejadian Asfiksianonatorum: di RS Muhammadiyah Palembang dengan menggunakan uji statistik Chi Square menyatakan bahwa ada hubungan yang bermakna antara umur kahamilan dengan asfiksia neonatorum dengan signfikasi $p$ value $(0,003)$.

Berdasarkan data dari Rumah Sakit Muhammadiyah Palembang Bayi Baru Lahir yang mengalami Kejadian Afiksia sebesar 101 di Rawat Inap Kebidanan di Ruangan Bayi Tahun 2017.

Berdasarkan data diatas maka peneliti tertarik untuk meneliti tentang Faktor-Faktor yang berhubungan dengan Kejadian Asfiksia pada Bayi Baru Lahir di Rumah Sakit Muhammadiyah Palembang Tahun 2017.

\section{METODE PENELITIAN}

Menurut jenisnya, penelitian ini adalah penelitian kuantitatif yang bersifat Deskriptif analitik dengan pendekatan retrospektif. Pendekatan retrospektif adalah suatu penelitian yang berusaha melihat kebelakang artinya pengumpulan data dimulai dari efek atau akibat yang telah terjadi. Sampel dalam penelitian ini adalah ibu bersalin dengan asfiksia pada bayi baru lahir yang berjumlah 81 bayi, teknik pengambilan sampel menggunakan symple random sampling. Penelitian ini dilaksanakan pada tanggal 16 Januari - 23 Januari 2018 di wilayah Rumah sakit Muhammadiyah Palembang. Teknik pengumpulan deta dengan data sekunder , yaitu mengambil daata di rekam medik. Pengolahan data yang digunakan dengan data sekunder melalui langkah-langkah , yaitu pengeditan data,pengolahan, tabulasi, entry data, pembersihan data, serta analisis data dengan teknik analisis univariat dan bivariat, dengan menggunakan uji statistik uji chi - square.

\section{HASIL PENELITIAN \\ Univariat}

Analisis univariat meliputi distribusi frekuensi masing-masing variabel independen, yaitu umur ibu, umur kehamilan, dan berat bayi baru lahir dengan variabel dependen yaitu kejadian asfiksia pada bayi baru lahir. Hasil univariat dapat dilihat dari tabel berikut :

Tabel 1

Distribusi Frekuensi Variabel Menurut Umur Ibu, Umur Kehamilan, dan Berat Bayi Baru Lahir di Wilayah Rumah Sakit Muhammadiyah Palembang Tahun 2017

\begin{tabular}{clcc}
\hline No & \multicolumn{1}{c}{ Variabel } & Frekuensi (f) & Presentase (\%) \\
\hline 1. & Umur Ibu & & \\
& - Risiko & 35 & 43,2 \\
& - Tidak Risiko & 46 & 56,8 \\
\hline \multicolumn{2}{l}{ Jumlah } & 81 & 100 \\
\hline 2. & Umur Kehamilan & & \\
& - Preterm & 21 & 25,9 \\
& - Aterm & 60 & 74,1 \\
\hline & Jumlah & 81 & 100 \\
\hline 3. & Berat Bayi Baru Lahir & & 25,9 \\
& - BBLR & 21 & 74,1 \\
\hline & - BBLN & 60 & 100 \\
\hline
\end{tabular}


Berdasarkan tabel 1 diatas diperoleh hasil distribusi frekuensi dari 81 responden, variabel umur ibu menunjukkan responden yang menyatakan berisiko sebanyak 35 responden (43,2\%), lebih sedikit dibandingkan dengan responden yang menyatakan tidak berisiko sebanyak 46 responden $(56,8 \%)$, distribusi frekuensi variabel umur kehamilan menunjukkan bahwa dari 81 responden, responden yang menyatakan aterm sebanyak 60 responden (74,1\%), lebih banyak dibandingkan dengan responden yang menyatakan preterm sebanyak 21 responden $(25,9 \%)$, distribusi frekuensi variabel berat bayi baru lahir menunjukkan bahwa responden yang menyatakan berat lahir bayi normal sebanyak 60 responden $(74,1 \%)$, lebih banyak dibandingkan dengan responden yang menyatakan berat bayi lahir renddah sebanyak 21 responden $(25,9 \%)$.

\section{Analisis Bivariat}

Analisis bivariat yang dilakukan terhadap dua variabel yang diduga dengan hubungan atau berkorelasi, yaitu variabel independen (umur ibu, umur kehamilan, dan berat bayi baru lahir) maupun variabel dependen (kejadian asfiksia). Analisis bivariat dapat dilihat dari tabel berikut :

\section{Tabel 2 Hubungan antara Variabel Independen Dengan Dependen}

\begin{tabular}{|c|c|c|c|c|c|}
\hline & & Kejadian & yi Baru Lahir & & \\
\hline & & & & & \\
\hline 1) & Umur Ibu & & & & \\
\hline & & 20 & 15 & 35 & \\
\hline & Risiko & $57,1 \%$ & $47.9 \%$ & $100 \%$ & 0,424 \\
\hline & & 21 & 25 & 46 & \\
\hline & Tidak Risiko & $45,7 \%$ & $54,3 \%$ & $100 \%$ & \\
\hline 2) & Umur Kehamilan & & & & \\
\hline & 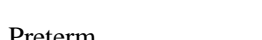 & 19 & 2 & 21 & \\
\hline & Preterm & $90,5 \%$ & $9,5 \%$ & $100 \%$ & 0,000 \\
\hline & & 22 & 38 & 60 & \\
\hline & Aterm & $36,7 \%$ & $63,3 \%$ & $100 \%$ & \\
\hline 3) & Berat Bayi Baru Lahir & & & & \\
\hline & BBLR & $\begin{array}{c}19 \\
905 \%\end{array}$ & $\begin{array}{l}2 \\
05 \%\end{array}$ & 21 & 0,000 \\
\hline & & 22 & 38 & 60 & \\
\hline & BBLN & $36,7 \%$ & $63,3 \%$ & $100 \%$ & \\
\hline
\end{tabular}

\section{Hubungan antara umur ibu dengan kejadian asfiksia}

Berdasarkan hasil univariat didapatkan hasil bahwa dari 81 responden, variabel umur ibu menunjukkan responden yang menyatakan berisiko sebanyak 35 responden (43,2\%), lebih sedikit dibandingkan dengan responden yang menyatakan tidak berisiko sebanyak 46 responden $(56,8 \%)$,

Berdasarkan hasil bivariat menunjukkan bahwa responden yang menyatakan berisiko dengan keajdian asfiksia sebanyak 20 responden $(57,1)$, lebih banyak dibandingkan dengan yang tidak berisiko sebanyak 21 responden $(45,7)$.
Dan hasil uji stastistik dengan menggunakan chi - squaare di dapatkan $p$ value $(0,424)$ berarti bahwa terdapat tidak ada hubungan yang signifikan anatara umur ibu dengan kejadian asfikisia di wilayah Rumah Sakit Muhammadiyah Palembang Tahun 2017.

Menurut Purnaningrum (2010) umur atau usia adalah satuan waktu yang mengukur waktu keberadaan suatu benda atau makhluk, baik yang hidup maupun yang mati. Semisal, umur manusia dikatakan lima belas tahun diukur sejak dia lahir hingga waktu umur itu dihitung.

Hal ini sejalan dengan penelitian Lestari, dkk (2013) di RSUD Penembahan 
Senopati Bantul dengan judul Induksi Persalinan dengan kejadian Asfiksia pada Bayi Baru Lahir menunjukan bahwa dari 235 responden $(73,44 \%)$ dan responden terkecil adalah kelompok umur $<20$ tahun yaitu 26 responden $(8,12 \%)$.

Berdasarkan hasil penelitian teori dan penelitian terkait, peneliti berasumsi bahwa umur ibu banyak yang tidak berisiko daripada berisiko hal ini menunjukkan bahwa setelah diteliti umur ibu yang berisiko belum tentu bayinya tidak asfiksia dan umur ibu yang berisiko belum tentu bayinya asfiksia.

\section{Hubungan antara umur kehamilan dengan kejadian asfiksia}

Berdasarkan hasil univariat didapatkan hasil bahwa dari 81 responden, responden yang menyatakan aterm sebanyak 60 responden $(74,1 \%)$, lebih banyak dibandingkan dengan responden yang menyatakan preterm sebanyak 21 responden $(25,9 \%)$.

Berdasarkan hasil bivariat menunjukkan bahwa responden yang menyatakan aterm dengan keajadian asfiksia sebanyak 22 responden $(36,7)$, lebih banyak dibandingkan dengan preterm sebanyak 19 responden (90,5). Dan hasil uji stastistik dengan menggunakan chi squaare di dapatkan $p$ value $(0,000)$ berarti bahwa terdapat ada hubungan yang signifikan antara umur kehamilan dengan kejadian asfikisia di wilayah Rumah Sakit Muhammadiyah Palembang Tahun 2017.

Hal ini sejalan dengan penelitian Sulistyorini, Suci (2014) di Rumah Sakit Muhammadiyah Palembang dengan judul gambaran umur ibu dan usia kehamilana ibu yang melahirkan bayi asfiksia menunjukan bahwa sebagian besar usia kehamilan ibu yang melahirkan bayi asfiksia adalah usia aterm $(63,4 \%)$.

Kehamilan merupakan proses fisiologis yang membutuhkan kanaikan proses metabolisme dan nutrisi untuk kebutuhan janin. Kehamilan adalah masa seseorang wanita membawa embrio atau fetus di dalam tubuhnya. Kehamilan manusia terjadi selama 40 minggu antara waktu menstruasi terakhir dan kelahiran 38 minggu pembuahan (Kusmiyati, 2013).

Hasil penelitian dan teori terkait, peneliti berasumsi bahwa umur kehamilan banyak yang aterm daripada preterm. Hal ini menunjukkan bahwa umur kehamilan preterm belum tentu bayinya akan asfiksia dan umur kehamilan yang aterm belum tentu bayinya tidak asfiksia.

\section{Hubungan antara berat bayi baru lahir lansia dengan kejadian asfikisa}

Berdasarkan hasil univariat didapatkan hasil bahwa dari 81 responden variabel berat bayi baru lahir menunjukkan bahwa responden yang menyatakan berat lahir bayi normal sebanyak 60 responden $(74,1 \%)$, lebih banyak dibandingkan dengan responden yang menyatakan berat bayi lahir rendah sebanyak 21 responden $(25,9 \%)$.

Berdasarkan hasil bivariat menunjukkan bahwa responden yang menyatakan berat bayi lahir normal dengan keajadian asfiksia sebanyak 22 responden (36,7\%), lebih banyak dibandingkan dengan berat bayi lahir rendah sebanyak 19 responden $(90,5)$. Dan hasil uji stastistik dengan menggunakan chi - squaare di dapatkan $p$ value $(0,000)$ berarti bahwa terdapat ada hubungan yang signifikan antara berat bayi baru lahir dengan kejadian asfikisia di wilayah Rumah Sakit Muhammadiyah Palembang Tahun 2017.

Hal ini sejalan dengan penelitian Fajarwati, dkk (2015) di RSUD Ulin Banjarmasin dengan judul hubungan antara berat badan lahir dan kejadian asfiksia neonatorum menunjukkan bahwa sebagian besar sempel dengan berat badan tidak berisiko tidak mengalami kejadian asfiksia yaitu sebesar $73,2 \%$, dan sebagian besar sempel dengan berat badan berisiko juga tidak mengalami kejadian asfiksia yaitu sebesar $75,9 \%$.

Menurut Dewi (2010) Bayi baru lahir disebut juga dengan neonatus merupakan individu yang sedang bertumbuh dan baru saja mengalami trauma kelahiran serta harus dapat melakukan penyesuaian diri dari 
kehidupan intaruterin ke kehidupan ekstrauterin. Bayi baru lahir normal adalah bayi yang baru lahir pada usia kelahiran 37 42 minggu dan berat badannya $2500-4000$ gram.

Berdasarkan hasil penelitian teori dan penelitian terkait, peneliti berasumsi bahwa berat bayi lahir bnayak yang berat badan lahir normal daripada bayi berat lahir rendah sehingga berat badan lahir normal belum tentu tidak terjadi asfiksia dan berat badan lahir rendah belum tentu terjadi asfiksia.

\section{KESIMPULAN}

1) Tidak Ada hubungan antara umur ibu dengan kejadian asfiksia pada bayi baru lahir di wilayah Rumah Sakit Muhammadiyah Palembang Tahun 2017, dengan $p$ value $(0,424)$.

2) Ada hubungan antara umur kehamilan dengan kejadian asfiksia pada bayi baru lahir di wilayah Rumah Sakit Muhammadiyah Palembang Tahun 2017 , dengan $p$ value $(0,000)$.

3) Ada hubungan antara berat bayi bru lahir dengan kejadian asfiksia pada bayi baru lahir di wilayah Rumah Sakit Muhammadiyah Palembang Tahun 2017 , dengan $p$ value $(0,000)$.

\section{SARAN}

1) Diharapkan bagi pihak Rumah Sakit melalui tenaga kesehatan, dapat memberikan informasi yang lengkap kepada keluarga dan lansia mengenai posyandu lansia, memberikan penyuluhan kesehatan, pemberian makanan bergizi, pengaktifan kelompok lansia dengan berbagai kegiatan kesehatan dan berbagi kegiatan lain di wilayah kerja Puskesmas 7 Ulu Palembang yang dilaksanan secara rutin setiap bulannya, sehingga masyarakat khususnya lansia dapat mengetahui posyandu lansia dan manfaatnya serta dapat meningkatkan pengetahuan lansia mengenai posyandu lansia dan manfaatnya.

2) Diharapkan kepada tenaga kesehatan atau kader posyandu agar dapat memberikan konseling kepada keluarga lansia tentang manfaat Posyandu Lansia, konseling agar keluarga memberikan dukungan kepada Lansia dan memberdayakan kader untuk dapat memberikan informasi kepada keluarga Lansia agar memberikan dukungan kepada Lansia untuk memanfaatkan Posyandu Lansia. Keluarga diharapkan juga memberikan dukungan konkrit seperti mengantar jemput lansia, sehingga dapatmempermudah akses lansia dalam memanfaatkan pelayanan Posyandu lansia.

\section{DAFTAR PUSTAKA}
Arif dan Kristiyana, Weni Sari.2009.Neonatus dan Asuhan.Jakarta: Nuha Offset.

Barbara, R.Stright .2005. Keperawatan ibu dan bayi baru lahir.Jakarta:Rineka Cipta.

Dewi, Vivian Nanny Lia Dewi.2014. Resusitasi Neonatus. Jakarta Selatan: Salemba Medika.

Dinas Kesehatan Kota Palembang. 2015. Profil Kesehatan Kota Palembang. Tersedia di: http://www.depkes.go.i d/resources/download/profil/PROFI L_KAB_KOTA_2014/1671_Sumse 1_Kota_Palembang_2014. [Diakses 3 Oktober 2017]

Gupde, 2011. Panduan Perawatan Anak. Jakarta: Pustaka Populer Obor.

Kosim, Sholeh.2003. Buku Panduan Manajemen Masalah Bayi, Baru Lahir Untuk Dokter, Perawat, Bidan di Rumah Sakit Rujukan Dasar. Jakarta: IDAI Departemen Kesehatan RI.

Ladewing, Patrcia .W dan London, Marcia .L dan Olds, Sally B.2006. Buku Saku Asuhan Ibu dan Bayi Baru Lahir, Jakarta: EGC 
Patiawati, Ika.2010. Bayi Dengan BBLR. Yogyakarta: Nuha Medika.

Manuaba. 2007. Ilmu Kebidanan, Penyakit Kandungan dan Keluarga Berencana untuk Pendidikan Bidan. Jakarta :

EGC

Notoatmodjo, Soekidjo. 2010. Metodologi Penelitian Kesehatan. Jakarta: Rineka Cipta.

Notoatmodjo, Soekidjo. 2011. Kesehatan Masyarakat Ilmu dan Seni. Jakarta: Rineka Cipta

Notoatmodjo, Soekidjo. 2012. Metodologi Penelitian Kesehatan. Jakarta: Rineka Cipta.

Saputra, Lyndon.2014.Catatan Ringkas Asuhan Neonatus Bayi dan Balita. Tangerang Selatan: Binarupa Aksara.

Saryono, Ari Setiawan. 2011. Metodologi Penelitian Kebidanan DIII, DIV, S1 dan S2. Yogyakarta: Nuha Medika.

Sondakh, Jenny J.S.2013. Asuhan Kebidanan Persalinan dan Bayi. Malang: Erlangga

Sulistyawati, Ari dan Nugraheny, Esti .2010. Asuhan Kebidanan Pada Ibu Bersali.Jakarta: Universitas Sumatera Utara

Sujarweni, Wiratna. 2014. Metodologi Penelitian. Yogyakarta: Pustaka Baru Press 